\title{
Antimicrobial effect of Anacardium occidentale leaf extract against pathogens causing periodontal disease
}

\author{
Jothi Varghese $^{1 *}$, Vijay Kumar Tumkur², Vasudev Ballal ${ }^{3}$, Giliyar Subraya Bhat ${ }^{4}$ \\ ${ }^{1}$ Department of Periodontics, Manipal College of Dental Sciences, Manipal University, Manipal, India \\ ${ }^{2}$ Department of Pharmacognosy, Manipal College of Pharmaceutical Sciences, Manipal University, Manipal, India \\ ${ }^{3}$ Department of Conservative Dentistry and Endodontics, Manipal University, Manipal, India \\ ${ }^{4}$ Department of Periodontology, College of Dentistry, University of Dammam, Dammam, Kingdom of Saudi Arabia \\ Email: ${ }^{*}$ jothimv@gmail.com
}

Received 3 May 2013; revised 4 June 2013; accepted 1 July 2013

Copyright (C) 2013 Jothi Varghese et al. This is an open access article distributed under the Creative Commons Attribution License, which permits unrestricted use, distribution, and reproduction in any medium, provided the original work is properly cited.

\section{ABSTRACT}

The oral cavity is perpetually colonized by different species of microorganisms and at times it is difficult to characterize the periodontal pathogen causing breakdown of tissue and bone. But over the years, based on scientific knowledge, it has been observed that various gram negative anaerobic bacteria have been involved with the initiation of periodontal disease. Based on literature reviews, a study was undertaken to investigate the antimicrobial effect of Anacardium occidentale (cashew) leaf extract on Porphyromonas gingivalis and Prevotella intermedia. Methanol and aqueous extracts of cashew leaves were prepared. Its antimicrobial activity against $P$. gingivalis and $P$. intermedia was tested using the agar diffusion method at various dilutions of $75 \mu, 50 \mu \mathrm{l}, 25 \mu \mathrm{l}, 10 \mu \mathrm{l}$ and $5 \mu \mathrm{l}$ respectively. $0.2 \%$ Clorhexidine gluconate (CHX) was used as control. Cultures of $P$. gingivalis and $P$. intermedia strains were maintained on Kanamycin blood agar. The agar plates were then incubated at $37^{\circ} \mathrm{C}$ for 72 hours after which the zone of inhibition was measured and the mean was recorded for each test solution. The results of this study demonstrated that, for both $P$. gingivalis and $P$. intermedia, the highest concentration $(75 \mu \mathrm{l})$ of both the extracts showed maximum antimicrobial action. For $P$. ginigvalis, the aqueous extract demonstrated significant inhibitory activity compared to the methanolic extract $(p=0.005)$, which was comparable to that of CHX. For $P$. intermedia, similar results were observed with aqueous extract being more effective compared to methanolic ( $p=\mathbf{0 . 0 0 7}$ ), however, $\mathrm{CHX}$ was most effective compared to both the extracts ( $p=$ 0.007). This study revealed that Anacardium occiden-

\footnotetext{
${ }^{*}$ Corresponding author.
}

tale leaf extracts have efficient antimicrobial activity against $\boldsymbol{P}$. gingivalis \& $\boldsymbol{P}$. intermedia. Hence, this preliminary study suggests that the antimicrobial action of $A$. occidentale leaf could be utilized for the preparation of chemical plaque control formulations.

Keywords: Agar Dilution Method; A. Occidentale Leaf; P. gingivalis; P. intermedia; Antibacterial Activity

\section{INTRODUCTION}

The mouth harbors a rich, diverse and complex microbial community. This highly diverse microflora inhabits various surfaces of the oral cavity causing a series of infections of the periodontal tissues which eventually can lead to loss of teeth. Periodontal disease is a common, slow, progressive inflammatory disease resulting from a complex biofilm of resident commensal and periodontopathic bacteria and their products. Along with the environment and host related factors, the microbes also form an integral part of the disease. Based on the prevalence of pathogens observed in periodontitis patients, it was observed that Porphyromonas gingivalis and Prevotella intermedia were most frequently recovered in patients showing angular pattern of bone loss [1].

$P$. gingivalis is a gram negative, anaerobic, black-pigmented species which colonizes the subgingival region. It is an opportunistic pathogen which intensively participates in the initiation and progression of periodontal disease [2]. $P$. gingivalis displays its virulence property by a variety of distinct adhesive interactions with the host, which may be in the form of fimbriae and outer membrane proteins $[3,4]$. Another gram negative, anaerobic, pigmented pathogen of considerable relevance in periodontal destruction is $P$. intermedia. Literature evidence suggests that $P$. intermedia plays a significant role 
in the pathogenesis of periodontal disease $[5,6]$. Both these species possess strong virulence factors and contribute to various forms of periodontal disease ranging from active to chronic $[7,8]$.

Chlorhexidine gluconate (CHX), a cationic bisbiguanide compound with high antibacterial activity, is one of the most commonly used chemotherapeutic agents against oral diseases. This is because of its wide spectrum of activity against gram positive, and gram negative bacteria including many anaerobic pathogens [9]. Chlorhexidine is also known to have a superior inhibitory effect on $P$. gingivalis [10]. It's effectiveness was also demonstrated in addition to daily plaque control, which significantly reduced $P$. intermedia [11].

Anacardium occidentale (Cashew) is a member of genus Anacardium belonging to family Anacardiaceae, which has its roots in different parts of the world. The cashew tree produces many resources and products. Various parts of the plant possess curative qualities like antidiabetic [12], antiinflammatory [12], antibacterial [13] and antifungal properties [14].

Srisawat et al. [15], studied the antibacterial effect of Anacardium occidentale, bark and leaf extract and found it to be effective in inhibiting $P$. gingivalis at low MIC concentrations.

Literature survey reveals scarce information on the antimicrobial effect of Anacardium occidentale leaf extract on $P$. gingivalis and P. intermedia. Hence, the aim of this study was to evaluate the antibacterial effect of two extracts prepared from cashew leaves against $P$. gingivalis and $P$. intermedia.

\section{MATERIALS AND METHODS}

\subsection{Collection of Anacardium occidentale Leaves}

The fresh leaves of the plant Anacardium occidentale $\mathrm{L}$. were collected from the cashew plantation area of Udupi, Karnataka, India during the month of September. Its botanical identity was authenticated by a botanist. A voucher specimen was deposited at the Department of Pharmacognosy, Manipal College of Pharmaceutical Sciences, Manipal University, Karnataka, India.

\subsection{Preparation of Extract}

The fresh leaves of $A$. occidentale were oven-dried and finely ground to coarse powder. The powdered material was subjected to maceration using methanol and water as a solvents. Two hundred grams of powder was mixed with 1 litre of Milli Q water with 5\% chloroform and alcohol and kept for 72 hours. Each mixture was stirred after every 8 hour using a sterile glass rod. At the end of extraction, each mixture was passed through Whatmann filter paper No. 1 by using a suction apparatus. The fil- trate obtained were concentrated with the help of rotary vacuum evaporator to get residue. Later, extracts were lyophilized and stored in a deep freezer at $-20^{\circ} \mathrm{C}$. The extractive value of the aqueous and alcohol extract in terms of yield was about $16.9 \%$ and $12.8 \%(\mathrm{w} / \mathrm{w})$ respectively. The prepared extracts were then used for the study.

\subsection{Evaluation of the Antimicrobial Activity}

The antimicrobial activity at different concentrations of two extracts (methanol and aqueous) of cashew leaf on the periodontopathogens were determined by employing the agar diffusion method. Culture strains of $P$. gingivalis (ATCC 33277) and P. intermedia (ATCC 25611) were maintained on Kanamycin agar plates. The kanamycin agar plates were prepared in sterile glass petri dishes, seeded with innocula and kept overnight under anaerobic conditions. A total of 33 wells ( 3 wells for each concentration of the extracts and CHX) of $6.0 \mathrm{~mm}$ in diameter and $4 \mathrm{~mm}$ deep were cut out on the seeded plates using sterile cork borer and each of the well was filled with the extracts of varying concentrations $(5,10$, $25,50,75 \mu \mathrm{l})$ and $0.2 \% \mathrm{CHX}$. Thus, a total of 66 wells were prepared for both the microorganisms. The extracts were allowed to diffuse into the medium and the plates were incubated at $37^{\circ} \mathrm{C}$ for 72 hours. The sensitivity of the tested pathogenic organisms to aqueous and methanolic extracts was shown by zones of inhibition after incubation. The zones of inhibition were measured using a plastic ruler.

For each concentration of the extract, the zone of inhibition was measured three times and the mean was re-corded. The statistical analysis was performed using the Kruskal wallis test and the Mann-Whitney "U" test. Significance for all statistical tests was predetermined at $\mathrm{p}<0.05$.

\section{RESULTS}

In the present study, the mean values of growth inhibition of $P$. gingivalis and $P$. intermedia, at different concentrations of both aqueous and methanolic extract of the leaves of A. occidentale were calculated and plotted against $0.2 \% \mathrm{CHX}$ which was used as a control (Figures 1 and 2). There were significant differences in the antimicrobial effects of both aqueous and methanolic extracts, with the aqueous extract being more effective than methanolic $(\mathrm{p}>0.05)$. For $P$. gingivalis, at the highest concentration of $75 \mu \mathrm{l}$, aqueous extract showed maximum antimicrobial activity than methanolic extract $(\mathrm{p}=$ 0.005), which was comparable to that of CHX $(p=0.015)$ (Figure 1). Similar results were observed with $P$. intermedia, in which the aqueous extract at $75 \mu 1$ dilution displayed significant inhibitory action than the methanolic extract $(p=0.007)$. However, in comparison to both the 
extracts, CHX showed better inhibitory action for $P$. intermedia $(\mathrm{p}=0.007)$ (Figure 2). The absence of zones of inhibition around each well signified resistance or no activity of the extracts, which was observed at the lower dilutions of $5 \mu 1,10 \mu \mathrm{l}$ and $25 \mu 1$ respectively (Figures 1 and 2).

\section{DISCUSSION}

The present study demonstrated that the aqueous extract presented better antimicrobial activity than the menthanolic extract. The presence of bioactive ingredients in the cashew leaves like carbohydrates, tannins, saponins, resins, alkaloids and flavanoids add to their antimicrobial activities. A phytochemical screening analysis on Anacardium occidentale leaves have showed the presence of high concentration of tannins in the aqueous extract and its absence in the alcoholic leaf extract [16]. This could probably account for the effective action of aqueous form compared to the methanolic extract in the inhibitory activity against $P$. gingivalis and $P$. intermedia. On the contrary, Ayepola and Ishola [17] evaluated the antimicrobial property of methanol and aqueous extracts of

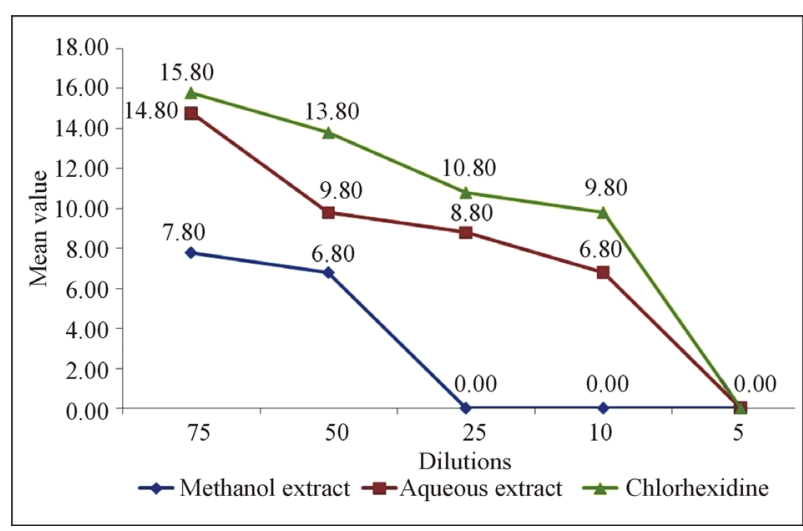

Figure 1. Effect of A. occidentate leaf extract on P. gingivalis.

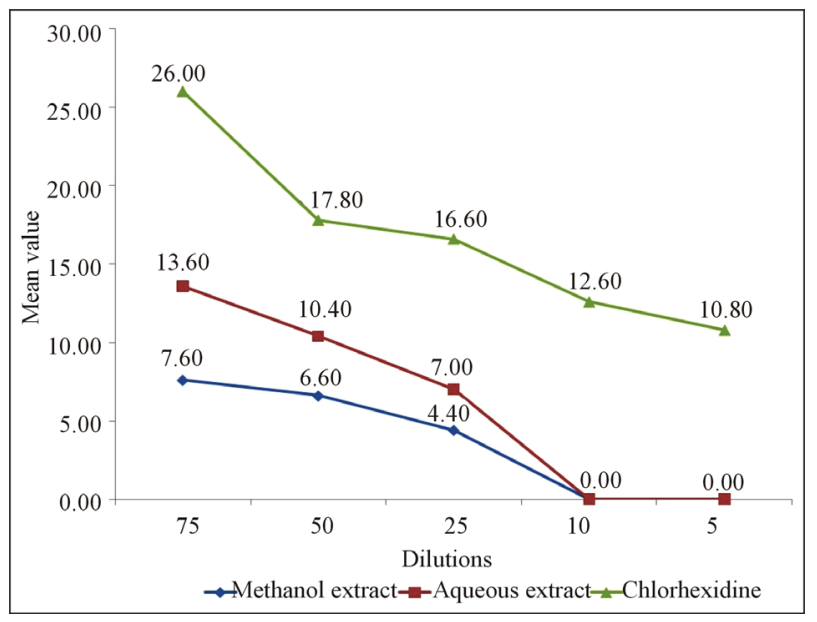

Figure 2. Effect of A. occidentate leaf extract on P. intermedia. the leaves of $A$. occidentale. They found the methanolic extract to be highly active against selected pathogens like Bacillus subtilis, Klebsiella pneumonia and E. coli. The authors linked the antimicrobial activity of methanol to its ability to obtain a broader range of antibacterial properties than the aqueous solvents. Tannins are polyphenols that can bind and precipitate proteins [18]. Ho et al. [19] studied the antimicriobial activity of six tannin components isolated from vaccinium vitis-idaea leaf extract against selected periodontal pathogens like $P$. gingivalis, $P$. intermedia and Actinobacillus actinomycetem comitans. The results showed that a few varieties of tannins had a strong antibacterial potential against $P$. gingivalis and $P$. intermedia. Hence, the authors of this study suggested beneficial tannins isolated from $V$. vitisidaea leaf extract could have beneficial effect for treatment of periodontal disease. Further studies are required to test the anti-bacterial property of tannin present in cashew leaf extract to explain the exact mechanism of action against these pathogens. The antimicrobial potential of aqueous extract was also demonstrated on $P$. intermedia, however, $0.2 \% \mathrm{CHX}$ performed the best action. The result of this study is in compliance with the previous work which showed, $0.2 \% \mathrm{CHX}$ to be effective against both organisms [20].

\section{CONCLUSIONS}

Herbal extracts contain a store of chemical constituents, which have been utilized on levels of their biological activities. These active ingredients present in medicinal plants have shown positive results in the management of various inflammatory diseases and may serve as an adjunctive treatment. This is a preliminary study which was done to investigate the antimicrobial property of Anacardium occidentale Leaf extract against $P$. gingivalis and $P$. intermedia.

Based on the results of this study, the following conclusions were drawn:

1) The leaf extract of $A$. occidentate has beneficial antimicrobial effects against pathogenic organisms involved in causing periodontal disease.

2) Also, further research has to be conducted for a wider understanding of these medicinal plants and for utilizing these cashew extract for prophylactic use.

\section{ACKNOWLEDGEMENTS}

A special recognition to the Late Mr. Acharya H, who was the inspiration for carrying out this study.

\section{REFERENCES}

[1] Monetti, M., Usin, M.M., Tabares, S., Gonzalez, A., Cabral, H.R. and Sembaj, A. (2012) The presence of perio- 
dontopathogens associated with the tumour necrosis factor-alpha expression in patients with different periodontal status. Acta Odontologica Latinoamericana, 25, 82-88.

[2] Darveau, R.P., Hajishengallis, G. and Curtis, M.A. (2012) Porphyromonas gingivalis as a potential community activist for disease. Journal of Dental Research, 91, 816820. doi:10.1177/0022034512453589

[3] Kubinowa, M., Hasagawa, Y. and Mao, S. (2008) P. gingivalis accelerates gingivial epithelial cell progression through the cell cycle. Microbes and Infection, 10, 122128. doi:10.1016/j.micinf.2007.10.011

[4] Grenier, D. and Dang La, Vu. (2011) Proteases of porphyromonas gingivalis as important virulence factors in periodontal disease and potential targets for plant-derived compounds: A review article. Current Drug Target, 12, 322-331. doi:10.2174/138945011794815310

[5] Haffajee, A.D. and Socransky, S.S. (1994) Microbial etiological agents of destructive periodontal diseases. $\mathrm{Pe}$ riodontology, 5, 78-111.

doi:10.1111/j.1600-0757.1994.tb00020.x

[6] Bragaa, R.R., Carvalhoa, M.A., Bru-a-Romeroa, O., Teixeiraa, R.E., Costab, J.E., Mendesc, E.N., Fariasa, L.M. and Magalhãesa, P.P. (2010) Quantification of five putative periodontal pathogens in female patients with and without chronic periodontitis by real-time polymerase chain reaction. Anaerobe, 16, 234-239. doi:10.1016/j.anaerobe.2010.02.007

[7] Bostanci, N. and Belibasakis, G.N. (2012) Porphyromonas gingivalis: An invasive and evasive opportunistic oral pathogen. FEMS Microbiology Letters, 333, 1-9. doi:10.1111/j.1574-6968.2012.02579.x

[8] Mombelli, A., Gmur, R., Frey, J., Meyer, J., Zee, K.Y., Tam, J.O., Lo, E.C., Di, R.J., Lang, N.P. and Corbet, E.F. (1998) Actinobacillus actinomycetem comitans and Porphromonas gingivalis in young chinese adults. Oral Microbiology and Immunology, 13, 231-237. doi:10.1111/j.1399-302X.1998.tb00701.x

[9] Tenenbaum, H., Jöelle, Luc., Schaaf, J.F., Federlin-Ducani, M., Cotton, C., Elkaim, R., Cuisinier, J.G.F. and Roques, C. (2011) An 8-week, randomized, controlled, clinical study of the use of a $0.1 \%$ chlorhexidine mouthwash by chronic periodontitis patients. Journal of Investigative and Clinical Dentistry, 2, 29-37.

[10] Solmaz, G. and Korachi, M. (2012) Inhibition and disruption properties of chlorhexidine gluconate on single and multispecies oral biofilms. Jundishapur Journal of Microbiology, 6, 61-66. doi:10.5812/jjm.4852

[11] Becerik, S., Türkoğlu, O., Emingil, G., Vural, C., Ozde- mir, G. and Atilla, G. (2011) Antimicrobial effect of adjunctive use of chlorhexidine mouthrinse in untreated gingivitis: A randomized, placebo-controlled study. Acta Pathologica, Microbiologica et Immunologica Scandinavic, 119, 364-372.

doi:10.1111/j.1600-0463.2011.02741.x

[12] Akinpelu DA. (2001) Antimicrobial activity of Anarcardium occidentale bark. Fitoterapia, 72, 286-287. doi:10.1016/S0367-326X(00)00310-5

[13] Doss, V.A. and Thangavel, K.P. (2011) Antioxidant and antimicrobial activity using different extracts of Anacardium occidentale L. International Journal of Applied Biology and Pharmaceutical Technology, 2, 436-443.

[14] Dahake, A.P., Joshi, V.D. and Joshi, A.B. (2009) Antimicrobial screening of different extract of Anacardium occidentale Linn. Leaves. Interdisciplinary Journal of Contemporary Research in Business, 1, 856-858.

[15] Srisawat, S., Teanpaisan, R., Wattanapiromsakul, C. and Worapamorn, W. (2005) Antibacterial activity of some thai plants against Porphymonas gingivalis. International Association for Dental Research, 20th Southeast asia Division \& Southeast Asia Association for Dental Education, 16th Annual Scientific Meeting, Malacca, 1-4 September 2005.

[16] Abulude, F.O., Ogunkoya, M.O. and Akinjagunla, Y.S. (2010) Phytochemical screening of leaves and stem of Cashew tree (Anacardium occidentate). Environmental Agricultural and Food Chemistry, 9, 815-819.

[17] Ayepola, O.O. and. Ishola, R.O. (2009) Evaluation of antimicrobial activity of Anacardium occidentale L. Advances in Medical and Dental Sciences, 3, 1-3.

[18] Chung, K.T., Wong, T.Y., Huang, Y.W. and Lin, Y. (1998) Tannins and human health: A review. Critical Reviews in Food Science and Nutrition, 38, 421-464. doi:10.1080/10408699891274273

[19] Ho, K.Y., Tsai, C.C., Huang, J.S., Chen, C.P., Lin, T.C. and Lin, C.C. (2001) Antimicrobial activity of tannin components from Vaccinium vitisidaea L. Journal of Pharmacy and Pharmacology, 53, 187-191. doi:10.1211/0022357011775389

[20] Vianna, M.E., Gomes, B.P.F.A., Berber, V.B., Zaia, A.A., Ferraz, C.C.R. and de Souza-Filho, F.J. (2004) In vitro evaluation of the antimicrobial activity of chlorhexidine and sodium hypochlorite. Oral Surgery, Oral Medicine, Oral Pathology, Oral Radiology and Endodontics, 97, 79-84. 